\title{
Resilient agri-food systems for nutrition amidst COVID-19: evidence and lessons from food-based approaches to overcome micronutrient deficiency and rebuild livelihoods after crises
}

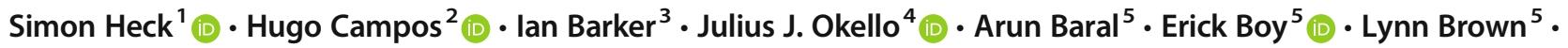 \\ Ekin Birol ${ }^{5}$ iD
}

Received: 20 May 2020 / Accepted: 30 June 2020 / Published online: 25 July 2020

(C) The Author(s) 2020

\begin{abstract}
COVID-19 has had an instant effect on food systems in developing countries. Restrictions to the movement of people and goods have impaired access to markets, services and food. Unlike other concurrent crises, rather than threatening the material hardware of food systems, COVID-19 has so far affected the 'software' of food systems, highlighting again that connectivity is at the heart of these systems. Drops in demand, the loss of markets and employment and growing concerns about international cooperation are indications of possible deeper disruptions to come. Amidst this uncertainty, strategies to safeguard food and nutrition security of the world's poor need to prioritize diversification of production and markets. Nutritious, biofortified crops such as potato, sweetpotato, but also wheat, maize and beans among others, can play a more significant role to provide key micronutrients (vitamin A, iron, zinc) at large scale. Strong local market chains, robust smallholder production systems and increasing commercial utilization make these crops powerful vehicles for securing nutrition when markets and mobility look uncertain. We posit that the evolving impacts of COVID-19 provide an opportunity to focus agricultural innovations, including the development and delivery of biofortified crops, on new and more specifically defined 'jobs to be done' throughout the food system. This will help bridge some of the current disruptions in supply and demand and will help prepare food systems for future crises.
\end{abstract}

Keywords COVID-19 $\cdot$ nutrition $\cdot$ biofortification $\cdot$ humanitarian crisis $\cdot$ food systems $\cdot$ potato $\cdot$ sweetpotato $\cdot$ innovation $\cdot$ jobs to be done theory

\section{Introduction}

The impact of COVID-19 on food systems was felt almost immediately. Restrictions to movement of people and goods meant that initially physical and soon economic access to markets, and to food, became disrupted irrespective of the pandemic's impact on food production. Wheat and rice prices have already jumped by $8 \%$ and $25 \%$ compared to

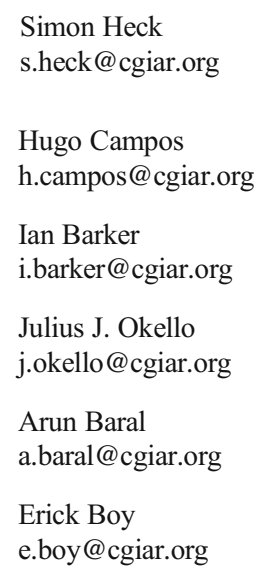

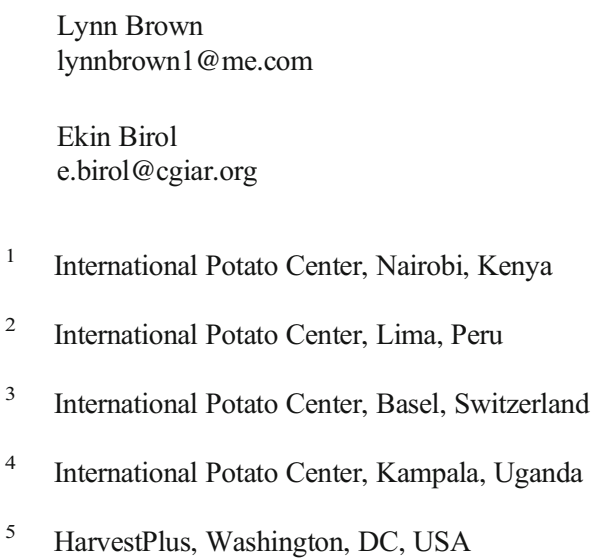


March 2019, respectively (Torero 2020). In this initial phase, COVID-19 has so far been a different kind of crisis from those sparked by natural disasters like the droughts, floods, cyclones and pests hitting the food systems of Africa and Asia over the past decades. COVID-19 has entered food systems through the disruption of markets, institutions and the workings of social capital that woven together are so important for the resilience of food systems. This is being particularly felt by the world's poor who rely more heavily on the informal sector and thus on daily economic and social transactions to maintain their livelihoods and get access to food.

Rather than threatening the 'material hardware' of food production, as other concurrent climatic and ecological crises do, COVID-19 has so far affected the 'software' of food systems. During the first three months, it has been a crisis of disrupted connections between supply and demand, even within seemingly well-established supply chains. Loss of markets and employment have left many millions of farmers and food sector workers wondering when and in what form their income opportunities will come back. In the longer term, through weakened economies, massive unemployment, increased draw on public sector resources, and greater uncertainty of international cooperation, COVID-19 might also lead to a wider crisis of food and nutrition security for some of the world's most vulnerable populations, in rural and urban communities. What are the implications of this kind of crisis for strategies to build more resilient food systems that can serve the priorities of the world's poor? Specifically, how can food systems keep generating nutrition and livelihood benefits for these vulnerable populations under COVID-19 conditions?

In this paper we reflect on how agricultural innovations can help meet these challenges, drawing specifically on experiences from utilizing potato, sweetpotato and the broader biofortification approach to improve nutrition and livelihoods during previous crises, and identifying key knowledge gaps emerging from COVID-19.

\section{Potato and sweetpotato - insights from crisis responses}

Given their comparative advantage as high yielding and fastgrowing crops with strong local market demand, and rather insulated from international price spikes, potato and sweetpotato have frequently been used as 'crisis response crops' following natural disasters in Africa and to some extent elsewhere. These crops also contributed to intensification and diversification of local food systems otherwise dominated by cereals, as in Asia, and thus helped strengthen their ability to withstand and recover from shocks (Prain and Naziri 2020). Evidence shows that farmers were able to quickly establish potato and sweetpotato fields once they received planting material and technical backstopping through emergency campaigns, and to maintain production for several years without further subsequent support. Their short growing cycles makes food, and feedstuff, available to affected households and communities faster and earlier in the season. Drought and disease tolerant varieties make harvests more reliable also under more marginal agro-ecological conditions. Surplus sales provide cash income that can be spent in meeting immediate food and non-food household needs (Okello et al. 2019). Moreover, these crops are naturally nutritious, and through breeding, the content of micronutrients has been increased, such as vitamin A in sweetpotato, and iron in potato. The former is already reaching millions of households in Africa, and the latter is at an advanced stage of development (Hannele Lindqvist-Kreuze, International Potato Center, pers. comm.). Research shows that households that plant improved varieties of these crops obtain higher yields and revenues, are less food insecure, and have more diverse diets and a better health status (Okello et al. 2017; Jones and de Brauw 2015; De Brauw et al. 2018; De Brauw et al. 2019).

In some cases, such emergency interventions provided an opportunity to accelerate the introduction of improved and more nutritious varieties at large scale, such as in Mozambique where nutritious biofortified sweetpotato varieties have been disseminated by Government and relief agencies during recurrent hunger relief programs over the past 10 years. As a result, about one third of Mozambique's sweetpotato today are vitamin A biofortified, making significant contributions to vitamin A consumption among rural populations with otherwise poor access to markets and health services (Jenkins et al. 2018). Similarly, the political unrest of 2008/09 in Kenya spurred the entry of the private sector into the supply of quality seed of improved potato varieties which carried important pro-poor traits. Likewise, the epidemics of maize lethal necrosis from 2012 onwards and fall army worm from 2018 in East Africa resulted in increasing production of alternative crops such as beans and potatoes as intercrops or part of a wider rotation (One Acre Fund 2019). These short cycle crops, which have always contributed to filling the hunger-gap on-farm before the maize harvest, went on to contribute to improved food security and nutrition at the national scale.

Turning crisis into opportunity for increasing access to nutritious crops, albeit through one-off interventions, can kickstart lasting change toward greater food and nutrition security where other efforts may have taken much longer. At field level, coordinated efforts to accelerate delivery of productive inputs and information are more likely during crises, and at policy level locally important crops receive greater attention from policy makers who otherwise are focused on a few internationally traded commodities. On the other hand, and relating these lessons to COVID-19, analyses also show that expanding access to larger populations and providing a 
pipeline of improved varieties over time also requires investment in the 'software' of local food systems (Worstell 2020). Creating connections to markets and institutional resources has been essential for sustaining the food security and nutrition benefits from these emergency responses. Supporting sustainable seed enterprises through technical training and facilitating their access to technologies and markets is an important element of this strategy. Experiences from Mozambique and Ethiopia illustrate this. Channeling recurrent emergency responses in Mozambique through a network of public and private sector seed multipliers built up local capacities for producing quality sweetpotato planting material over time that could be activated in 2019 to respond almost immediately to the food emergency following cyclone Idai. Within only six months, 14,000 new households in the worst hit areas were able to grow improved, climate resilient biofortified sweetpotato varieties (International Potato Center 2019a). In Ethiopia, during the 2016 drought, 10,000 households quickly received potato and sweetpotato seed through local suppliers accompanied by additional information on improved seed management to strengthen their capacity for dealing with future shortfalls (International Potato Center 2019b).

Seed enterprises can thus become multi-functional, trading seed and information for a range of crops, and contributing directly to diversification and hence resilience of local food systems. These rural enterprises and their networks of suppliers and customers can also be effective partners in future crisis responses, providing sources of seed and food for humanitarian efforts closer to locations of need and thus linking food or seed deficit areas to suppliers in the same country. COVID-19, at least in the short term, poses additional constraints at an operational level through restrictions to movement and assembly that require changes to how goods and services are being delivered. Already, the innovation capabilities and economies of scale of the ICT sector have started to transform the world's food systems (World Bank 2019). Bringing this capacity to bear on the needs of smallholder farmers and poor consumers at the bottom of the pyramid should be relatively easy with the right partnerships.

\section{Safeguarding nutrition through biofortification of staple crops}

Biofortification, the enrichment of commonly consumed staple crops with nutrients such as vitamin A, iron, and zinc, has proven to be an efficacious, acceptable and cost-effective solution for reducing deficiencies in these micronutrients, and in improving various health outcomes (Bouis \& Saltzman 2017; Bouis et al. 2019; Birol \& Bouis 2019). These benefits are critical both during the COVID-19 humanitarian crisis and its aftermath. Research has shown that the amounts of these micronutrients found in healthy, diversified diets have a beneficial effect on the human immune system including its ability to counter some types of viruses (Wessels et al. 2017; Read et al. 2019). An estimated 2.5 billion people are at risk of micronutrient deficiencies (Saltzman et al. 2017) as their diets do not meet their biological requirements for these micronutrients. This 'hidden hunger' is expected to increase as a result of disruptions to the global food systems due to COVID-19 (see United Nations System Standing Committee on Nutrition) if lessons from the global food price crisis of over a decade ago also apply today (Christian 2010). While important differences in the nature of these crises and their likely effects on food systems have been pointed out, some key parallels exist that pose threats to nutrition and micronutrient supplies in particular.

An immediate negative impact of COVID-19 has been the decline in household incomes, especially for the majority of the poor in LMICs who work in the informal sector. This is further compounded by the sharp decline in remittances to LMICs already projected by the World Bank for 2020, which further impairs the food purchasing power of vulnerable populations. Lower household incomes often translate into shifts in food consumption patterns, increasing reliance on staples to meet caloric needs (Bouis et al. 2011) and lowering consumption of more expensive, nutrient dense animal source foods, fruits and vegetables. This trend may be further exacerbated during COVID-19 in countries where disruptions to transportation and restricted mobility of farm labor jeopardizes supply chains of perishable horticultural crops and animal source foods thus increasing their prices and putting them further out of reach of poor families.

Restrictions may have similar effects on the delivery of other important micronutrient supply strategies. Industrial fortification of commonly consumed foods (such as flour, oil and sugar) is widely effective in reaching consumers also in urban markets, but may also become disrupted should supplies of fortificants, factory operations, inspection and support services, transportation and marketing of fortified products be affected. Initiatives in the health sector, such as Vitamin A supplementation programs, may also be disrupted at least in the short run through shifts of resources toward COVID-19 testing and treatment, and through constraints from social distancing rules for program delivery. In sum, falling incomes, market disruptions, increasing prices of nutrient-dense foods, and shifting policy priorities caused by COVID-19 are likely to increase the importance of biofortified staples as a reliable, fast and affordable source of micronutrients.

Biofortification could help address some of the long-term concerns about building 'micronutrient resiliency' among food and nutrition insecure populations in expectation of future pandemics or other crises. Where biofortified crops are well integrated in local food production systems and reliably and affordably deliver key micronutrients alongside basic calories, this resiliency will be strengthened. Great progress is 
being made in achieving the potential of biofortification, specifically through accelerated development and deployment of new varieties. Almost 350 biofortified varieties of $11 \mathrm{key}$ staples are released for production in 40 countries globally (see this map of which biofortified crops are available where). Over the past 10 years, the work by the CGIAR's HarvestPlus and CIP and their partners has enabled an estimated 15 million households to grow biofortified crops, including orange-fleshed sweetpotato, across Africa, Asia and Latin America.

At the same time, COVID-19 raises new questions and opportunities for scaling up biofortification to reach much larger populations, both farmers and consumers, in many more countries. Since biofortified staple crops are produced and consumed locally (if not on farm) and since several of them (such as vitamin A maize, iron beans and pearl millet, and zinc rice, maize and wheat) tend to have long shelf lives, their integration in food systems would provide micronutrient resiliency for farming households and local consumers whose purchasing power and access to markets is impaired as a result of pandemics. This micronutrient resiliency is also likely to improve consumers' resilience to potential future pandemics given the aforementioned proven impact of micronutrient status on human immune function. As a result of COVID-19, HarvestPlus and CIP have turned to digital technologies and strategies avoiding physical contacts for reaching farmers and consumers with information about the benefits, availability and sources of biofortified seeds and foods, as well as accelerated partnerships with public and humanitarian sectors, for delivery of both biofortified seeds and food to populations most vulnerable to food and nutrition insecurity. As they pivot the delivery models for biofortified seeds and food due to COVID-19, CIP and HarvestPlus are implementing a rigorous learning agenda around these innovations to better understand their cost-effectiveness, equity, impact and scalability aspects so as to be even better prepared for the next crisis.

\section{The job to be done: Directing agricultural innovation to meet the needs of the poor}

Looking ahead, while we cannot foresee the depth, length and nature of the food and nutrition security fallout from COVID19 , we should take the current uncertainties as a further reminder of how much is at stake for the world's poor and how much we still have to learn about addressing their needs through the rich set of technologies and knowledge we have developed. It starts with identifying the 'job to be done', the problem to be solved from the perspective of those whose problem it is, in this case the poor that are vulnerable to recurrent crises. The 'job to be done' theory, developed at Harvard Business School, provides a customer-driven framework for innovation which puts the needs of the customer at its center
(Christensen et al. 2016). It has been implemented in many innovation efforts of both private and public sectors. Campos (2020) makes a strong case for applying this perspective to addressing agricultural and food systems challenges and lays out why this is a non-trivial first step when trying to solve familiar but wicked problems, more so under conditions of uncertainty. A preliminary analysis of the COVID-19 food systems implications so far suggests several 'jobs to be done'. As noted widely, restrictions from the pandemic response in several countries have led to short term disconnects between consumers without physical access to food and producers without marketing outlets. This has affected in particular the marketing of perishable nutritious foods. Expecting that such disruptions may re-occur with future waves and new pandemics, there may be need to diversify market supply chains to ensure that such foods can be sourced from shorter distances or can be stored safely and economically in a processed form that still meets the food preferences of consumers. More needs to be understood about supply chain and technology options for 'stabilizing' the supply of key nutrients from nutrient-dense foods, including biofortified crops and horticultural produce, to lowincome consumers through diverse market chains of processed and fresh products. A 'job to be done' perspective will caution us not to prescribe solutions off the shelf, but co-create options with consumers, retailers, service providers and farmers. Addressing the needs and satisfaction gaps of end-users becomes the goal and starting point of agricultural innovation - also when combating undernourishment and micronutrient insecurity.

A second, and more fundamental market disruption from COVID-19 has been the decline of purchasing power among many millions of already poor consumers following their loss of jobs and incomes. This has often been compounded by their relocation from familiar social and economic environments around their places of employment for an undefined length of time. At this time, it is unclear how deep and long this disruption will be and how it will affect food access for different categories of these consumers in different market segments and market contexts. This uncertainty raises the issue of scale and agency when prioritizing among potential response strategies. From the consumer's perspective, the 'job to be done' will most likely center around securing reliable and affordable access to familiar food items though they might be willing to compromise on food selection under restricted circumstances. For the farmers, traders and retailers, the problem to be solved at this time will have more to do with timing of harvests, selling through existing supply chain agreements, and managing stockpiles - all in a manner that minimizes losses and potentially creates opportunities for incremental gain from shifting consumer demand. From a public sector 
viewpoint, the 'job to be done' will however include concerns about social stability and nutrition and health risks from this decline in purchasing power that includes large number of young wage earners, both women and men, with children under five and two years of age.

\section{Conclusion}

Niels Bohr's quote 'Prediction is very difficult, especially about the future' appears more relevant than ever. Nevertheless, building from previous experiences and incorporating novel perspectives such as 'the job to be done', it is possible to conceive how to mitigate the consequences of this humanitarian crisis: In the very short term (weeks to months), it is essential to keep food flowing and to enable migrant workers to move and access health checks. This will help stabilize food prices and markets to continue operating. To achieve this, policy makers need to carefully consider the far-reaching consequences of export control measures and restrictions in regional cross-border trade. In the short term (next 12 months), farmers require reliable access to seed and other productive inputs so they can produce the food and feed they need to support their families and sell their surplus. Biofortified crops can make a particular contribution in this regard. In the mid to long term (next 2 years), food systems need to invest in diversification and connectivity to manage increased interdependence as core strategies for building resilience to the 'unknown unknowns' lying ahead.

Crises such as the Covid-19 pandemic and others whether natural or man-made seem to drive both technological and system changes that foster innovation and hopefully continually build resilience against future shocks. As an example, we are already seeing Kenyan private rose growers turning their capacity and knowledge to producing potato apical rooted cuttings for sale to local seed producers when faced with the loss of their export trade. Diverting even a small proportion of the production capacity of the very capable East African export flower and vegetable sector to local food production may in the future build resilience for both the exporters, local seed producers and for food security in general.

If COVID-19 has so far been a crisis of disrupted connections, it is also a reminder that connectivity between people and resources lies at the heart of functioning food systems which in turn are essential to our ability to cope with global crises; or in John Boyd Orr's words, "We cannot build peace on empty stomachs".

Acknowledgements SH, HC, IB and JO's work was undertaken as part of, and funded by, the CGIAR Research Program on Roots, Tubers and Bananas (RTB) and supported by CGIAR Trust Fund contributors (https://www.cgiar.org/funders/).
SH acknowledges the support of the UK Department for International Development awarded to the International Potato Center.

$\mathrm{HC}$ acknowledges the support of the Bill and Melinda Gates Foundation's investment (OPP1213329) awarded to the International Potato Center (SweetGAINS) which also covered the Open Access license of this article.

$\mathrm{AB}, \mathrm{EB}, \mathrm{LB}$ and EB's work was undertaken as part of, and funded by, HarvestPlus. HarvestPlus' principal donors are the UK Government; the Bill \& Melinda Gates Foundation; the US Government's Feed the Future initiative; the European Commission; and donors to the CGIAR Research Program on Agriculture for Nutrition and Health (A4NH). HarvestPlus is also supported by the John D. and Catherine T. MacArthur Foundation.

Authors' contributions Simon Heck, Hugo Campos and Ian Barker contributed to the study conception and design. The first draft of the manuscript was written by Simon Heck. Ekin Birol, Hugo Campos, Ian Barker and Julius Okello commented on previous versions of the manuscript. All authors read and approved the final manuscript.

\section{Compliance with ethical standards}

Conflict of interest The authors declared that they have no conflict of interest.

Ethics approval Not applicable

Consent to participate Not applicable

Consent for publication Not applicable

Availability of data and material Not applicable

Code availability (software application or custom code)

Open Access This article is licensed under a Creative Commons Attribution 4.0 International License, which permits use, sharing, adaptation, distribution and reproduction in any medium or format, as long as you give appropriate credit to the original author(s) and the source, provide a link to the Creative Commons licence, and indicate if changes were made. The images or other third party material in this article are included in the article's Creative Commons licence, unless indicated otherwise in a credit line to the material. If material is not included in the article's Creative Commons licence and your intended use is not permitted by statutory regulation or exceeds the permitted use, you will need to obtain permission directly from the copyright holder. To view a copy of this licence, visit http://creativecommons.org/licenses/by/4.0/.

\section{References}

Birol, E. \& Bouis, H. E. (2019). Leveraging biofortified crops and foods: R4D perspective. In Encyclopedia of Food Security and Sustainability Vol 2. Pp. 181-188. https://doi.org/10.1016/B978-008-100596-5.22450-5

Bouis, H., Eozenou, P., \& Rahman, A. (2011). Food prices, household income, and resource allocation: socioeconomic perspectives on their effects on dietary quality and nutritional status. Food and Nutrition Bulletin, 32(1), S14-S23. 
Bouis, H. \& Saltzman A. (2017). Improving nutrition through biofortification: A review of evidence from HarvestPlus, 2003 through 2016. Global Food Security, 12, 49-58.

Bouis, H. E., Saltzman, A., \& Birol, E. (2019). Improving nutrition through biofortification. In Agriculture for improved nutrition: Seizing the momentum. Chapter 5. Fan, Shenggen; Yosef, Sivan; Pandya-Lorch, Rajul (Eds.). Wallingford, UK: International Food Policy Research Institute (IFPRI) and CABI. http://ebrary.ifpri.org/ $\mathrm{cdm} / \mathrm{ref} /$ collection/p15738coll2/id/133096

Campos, H. (2020). The Innovation revolution in agriculture - A roadmap to value creation. Switzerland: Springer In press. ISBN 978-3-030-50991-0.

Christensen, C. M., Hall, T., Dillon, K., \& Duncan, D. (2016). Know Your Customers' "Jobs to Be Done". Harvard Business Review, (September issue), 425-434.

Christian, P. (2010). Impact of the Economic Crisis and Increase in Food Prices on Child Mortality: Exploring Nutritional Pathways. Journal of Nutrition, 140(1), 177S-181S.

De Brauw, A., Eozenou, P., Gilligan, D. O., Hotz, C., Kumar, N., \& Meenakshi, J. V. (2018). Biofortification, crop adoption and health information: impact pathways in Mozambique and Uganda. American Journal of Agricultural Economics, 100(3), 906-930.

De Brauw, A., Moursi, M., \& Munhaua, A. (2019). Vitamin A intakes remain higher among intervention participants 3 years after a biofortification intervention in Mozambique. British Journal of Nutrition, 122(10), 1175-1181. https://doi.org/10.1017/ S0007114519002162

International Potato Center. (2019a). Cyclone Idai: Jump-starting farmer recovery in Mozambique. Outcome story. Lima: International Potato Center 2p.

International Potato Center. (2019b). Gender-sensitive emergency responses with potato and sweetpotato, Ethiopia. Rebuilding food security after drought. Project profile. Lima: International Potato Center 2p.

Jenkins, M., Shanks, C. B., Brouwer, R., et al. (2018). Factors affecting farmers' willingness and ability to adopt and retain vitamin A-rich varieties of orange-fleshed sweet potato in Mozambique. Food Security., 10, 1501-1519. https://doi.org/10.1007/s12571-0180845-9.

Jones, K. M., \& de Brauw, A. (2015). Using agriculture to improve child health: promoting orange sweet potatoes reduces diarrhea. World Development, 74, 15-24

Okello, J. J., Zhou, Y., Kwikiriza, N., Ogutu, S., Barker, I., SchulteGeldermann, E., Ochieng, B., \& Ahmed, J. T. (2017). Productivity and food security effects of using of certified seed potato: the case of Kenya's potato farmers. Agriculture \& Food Security, 6(1), 25.

Okello, J., Zhou, Y., Barker, I., \& Schulte-Geldermann, E. (2019). Motivations and Mental Models Associated with Smallholder Farmers' Adoption of Improved Agricultural Technology: Evidence from Use of Quality Seed Potato in Kenya. The European Journal of Development Research, 31(2), 271-292.

One Acre Fund. (2019). Responding to Fall Army Worm Outbreaks in Africa. Report to USAID. 13p. https://oneacrefund.org/documents/ 345/One_Acre_Fund_USAID_FAW_Report_April 2019.pdf

Prain, G., \& Naziri, D. (2020). The role of root and tuber crops in strengthening agri food system resilience in Asia. A literature review and selective stakeholder assessment. Food Resilience Through Root and Tuber Crops in Upland and Coastal Communities of the Asia-Pacific (FOODSTART+) Project. Lima: Peru. International Potato Center. ISBN: 978-92-9060-539-3. 58pp.
Read, S.A., Obeid, S., Ahlenstiel, C., \& Ahlenstiel, G. (2019). The Role of Zinc in Antiviral Immunity. Advances in Nutrition, 10(4), 696710

Saltzman, A., Birol, E., Oparinde, A., Andersson, M., Asare-Marfo, M., Diressie, M., Gonzalez, C., Lividini, K., Moursi, M., \& Zeller, M. (2017). Availability, production, and consumption of crops biofortifed by plant breeding: current evidence and future potential. Annals of the New York Academy of Sciences, 1390(1), 104-114.

Torero, M. (2020). Without food, there can be no exit from the pandemic. Nature, 580, 588-589.

Wessels, I., Maywald, M., \& Rink, L. (2017). Zinc as a Gatekeeper of Immune Function. Nutrients, 9, 1-44.

World Bank. (2019). Future of Food: Harnessing Digital Technologies to Improve Food Systems Outcomes. Washington, DC: The World Bank Group 42p.

Worstell, J. (2020). Ecological Resilience of Food Systems in Response to the COVID-19 Crisis. Journal of Agriculture, Food Systems, and Community Development, 9(3), 23-30. https://doi.org/10.5304/ jafscd.2020.093.015.

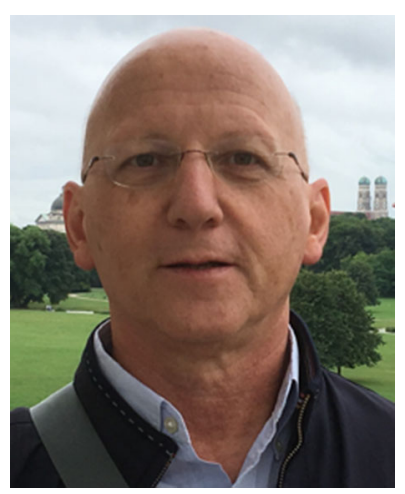

Simon Heck is the Program Director for Sweetpotato Agrifood Systems at the International Potato Center (CIP). Based in Kenya, he oversees a global research portfolio in Africa, Asia and Latin America focused on developing and delivering improved sweetpotato and other nutritious crops to strengthen livelihoods and nutrition outcomes for the poor. A social scientist, his own research interest is in food systems transformation and its relation to social and environmental change. He holds a $\mathrm{PhD}$ from Boston University and has previously worked with the WorldFish Center, the International Union for Conservation of Nature (IUCN), and the UK Department for International Development (DFID) in Africa and the Middle East.

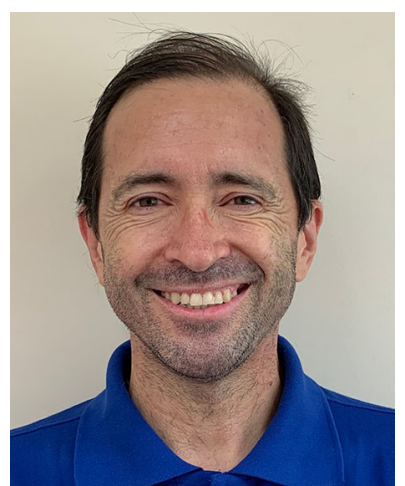

Hugo Campos ( $\mathrm{PhD}, \mathrm{MBA})$ is Director of Research at the International Potato Center, and obtained his Ph.D. at the John Innes Center in the United Kingdom. He has $20+$ years of international corporate and development experience, and his research interests are the genetic improvement of crops, and the management of innovation. He has lived in many Latin American countries, the United States and the United Kingdom. 


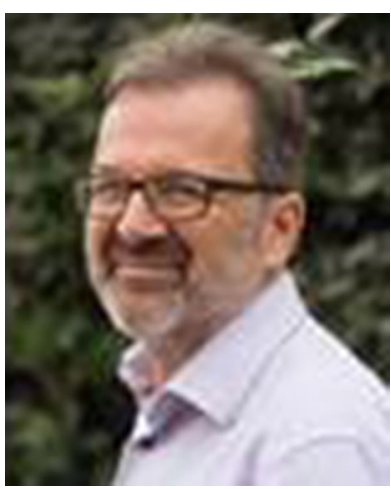

Ian Barker $(\mathrm{PhD})$ is the Global Potato Agri-Food Systems Program Director at the International Potato Center (CIP). He leads an innovative portfolio of research and development projects designed to intensify, diversify and strengthen the resilience of agri-food systems with potato-related technologies. His own research interests include the role of public-private partnerships in the delivery of seeds to small-holder farmers. He previously lived and worked in the UK, Peru and Kenya and is now based in Switzerland.

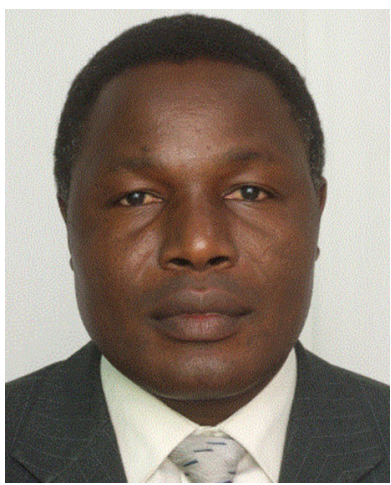

Julius Juma Okello, $\mathrm{PhD}$ is an Impact Assessment Specialist at International Potato Center with extensive experience in monitoring and impact evaluation of development projects and programs. $\mathrm{He}$ has PhD in Agricultural Economics with specializations in International Agricultural Development and Resource and Environmental Economics. Since 2013, he has worked in several projects focusing on household food and nutrition security across sub-Sahara Africa. His research focuses on understanding the adoption and impact of improved potato and sweetpotato varieties on farm household welfare; the impact of agriculture-nutrition-health interventions on household nutrition outcomes; and the role of behavioural and social sciences in explaining farmer and consumer behaviour and decision-making. He is widely published in these areas.

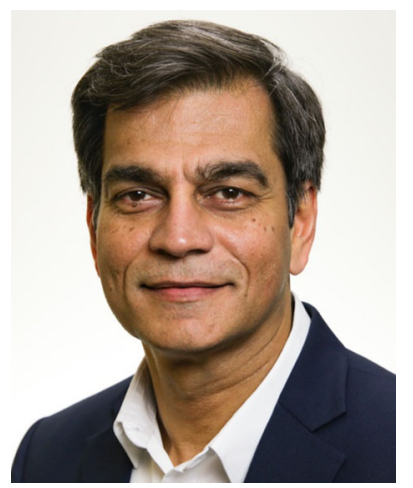

Arun Baral was appointed chief executive officer (CEO) of HarvestPlus on July 1, 2019, succeeding HarvestPlus founder Howarth Bouis. As CEO, Baral oversees the interdisciplinary, global effort of HarvestPlus to develop and deliver micronutrientrich staple food crops to reduce micronutrient deficiency (or "hidden hunger") among malnourished populations. He champions biofortification within the CGIAR system, the private sector, among national agricultural research centers, and in the international agriculture and nutrition communities. He focuses on developing effective partnerships to scale up biofortification and support development of sustainable biofortified food systems that provide access to nutritious food for all. Baral also spearheaded the establishment of HarvestPlus Solutions, a non-profit entity that is working with partners in the private and public sector to fill gaps in biofortified food value chains to scale up biofortified products. Baral joined
HarvestPlus in 2017 as chief financial officer, after more than 30 years in the international agriculture sector, with roles in commercial operations, profit and loss (P\&L) management, strategy, finance, business development, and marketing. He has been based in Asia, Africa, and the United States, and has also traveled extensively for work in Latin America. Baral spent over 24 years at DuPont Pioneer, including as Asia Regional Business Director, where he was instrumental in developing and executing a strategy that significantly grew the Asia business during his tenure. Baral holds a Master of Business Administration from Drake University in Iowa, and a Bachelor of Commerce (honors) from Delhi University in India.

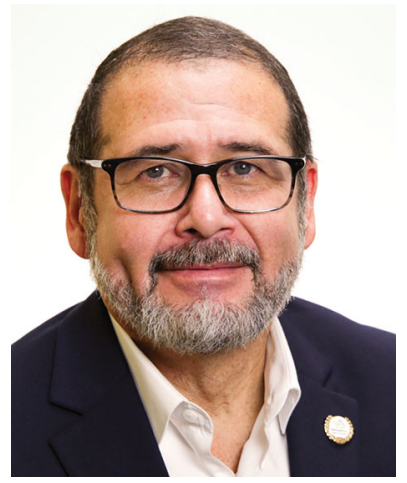

Erick Boy joined HarvestPlus in 2008 as the Head of Nutrition and Chief Nutritionist. Previously he spent nine years at Nutrition International, where he developed and managed the iron and zinc research portfolios, established a consultative group of nutrition experts, promoted the adoption of micronutrient powders and introduced zinc supplements in Latin America. During the previous 10 years he worked at the Institute of Nutrition of Central America and Panama, providing technical assistance in maternal nutrition and iodine deficiency control to the health ministries of member countries. In his current role, Boy leads the nutrition unit, which commissions crop related research studies comprising biomarkers development, food consumption and composition, deficiency prevalence, nutrient retention, micronutrient bioavailability, and the efficacy of biofortified crops. He manages relations with nutrition research collaborators, the World Health Organization and the Micronutrient Forum, and other programs that specialize in micronutrient nutrition. He is a member of IFPRI's Institutional Review Board, the editorial board of the Food and Nutrition Bulletin, and the steering committee of the BRINDA working group. Boy obtained his medical degree from the San Carlos University in Guatemala and his $\mathrm{PhD}$ in nutrition from the University of California at Davis.

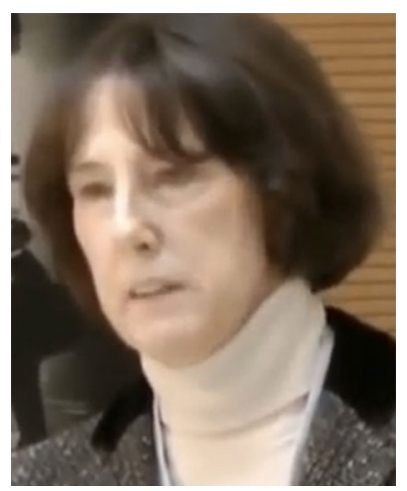

Lynn Brown is a post graduate trained economist specialized in gender, food and nutrition policy, social protection, agriculture and rural development. She has extensive experience in Africa and Asia, including two years in Bangladesh managing the World Bank's nutrition portfolio. Brown was the first Chief Economist of the World Food Program and enjoyed a long career at the World Bank. She is now an independent consultant, including roles as Senior Adviser at HarvestPlus. She is an author of numerous research papers, book chapters, and co-editor of a book on gender and structural adjustment. 


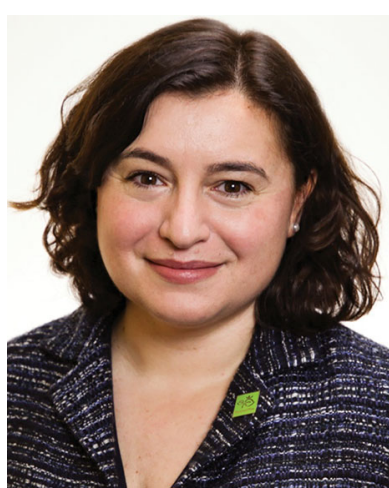

Ekin Birol is the Director of Impact and Strategy at HarvestPlus. Birol has over 20 years of international experience working effectively with universities, research centers, donors, $\mathrm{CSOs}$, and public and private sectors in countries of all regions. In 2010, after three years as a research fellow with the Markets, Trade and Institutions Division of the International Food Policy Research Institute (IFPRI), Birol joined HarvestPlus in her current position. The department's 10 full time staff working closely with some 40 collaborators to conduct research to inform the development of targeted and cost-effective biofortification interventions; to estimate their acceptance, reach and effectiveness and to communicate research results to a wide range of audiences. Birol holds a $\mathrm{PhD}$, MPhil, MSc, and BSc (Honors) from the Department of Economics at University College London. She was a postdoctoral research fellow at the University of Cambridge. In 2010 and 2014, Birol received special awards in recognition of her outstanding accomplishments as an IFPRI/ HarvestPlus employee. She has published two edited volumes, over 40 peer-reviewed journal articles, and over 30 chapters in edited volumes. 